\title{
Compositional Variants of Cu-rich Precipitate in Thermally Aged Ferritic Steel
}

\author{
Qingdong Liu ${ }^{1,2,3} \cdot$ Yihua Chen ${ }^{1}$ Chuanwei $\mathrm{Li}^{1} \cdot$ Jianfeng Gu ${ }^{1,2}$
}

Received: 9 June 2017/Revised: 15 September 2017/Published online: 16 October 2017

(C) The Chinese Society for Metals and Springer-Verlag GmbH Germany 2017

\begin{abstract}
Atom probe tomography was utilized to investigate $\mathrm{Cu}$ precipitation in a high-strength low-alloy steel isothermally aged at $500{ }^{\circ} \mathrm{C}$ for $1,4,16$, and $64 \mathrm{~h}$ after water-quenching from $900{ }^{\circ} \mathrm{C}$. With prolonged aging time, the $\mathrm{Cu}$ rich precipitates (CRPs) increased in size and decreased in number density, and gradually evolved from spheroidal to elliptical in morphology. The small CRPs were rich in a high amount of Fe and a certain amount of $\mathrm{Ni}$ and Mn at their early nucleation stage. The large CRPs with increased size due to extensive aging contained less $\mathrm{Fe}$ and more $\mathrm{Cu}$ at their later growth stage. Additionally, $\mathrm{Ni}$ and $\mathrm{Mn}$ were both readily to segregate at the CRP/matrix heterophase interfaces, and $\mathrm{Mn}$ was higher in content than $\mathrm{Ni}$ in the precipitate interior especially when the CRPs were large in size.
\end{abstract}

KEY WORDS: High-strength low-alloy steel; Thermal aging; Cu-rich precipitate; Atom probe tomography

\section{Introduction}

High-strength low-alloy (HSLA) steels are widely used as structural components of ship hulls, pipelines, bridges, etc., in modern industry, which are newly designed to obtain the combination of high strength, excellent ductility, and good toughness to insure the reliability in the increasingly harsh conditions during service. Cu precipitation in HSLA steels

Available online at http://link.springer.com/journal/40195.

Jianfeng $\mathrm{Gu}$

gujf@sjtu.edu.cn

1 Institute of Materials Modification and Modelling, School of Materials Science and Engineering, Shanghai Jiao Tong University, Shanghai 200240, China

2 Collaborative Innovation Center for Advanced Ship and Deep-Sea Exploration, Shanghai Jiao Tong University, Shanghai 200240, China

3 Scholl of Nuclear Science and Engineering, Shanghai Jiao Tong University, Shanghai 200240, China is highly related with their mechanical properties and thus becomes an important hotspot industrially and scientifically. $\mathrm{Cu}$ is often artificially added in traditional HSLA steels such as shipbuilding steels to achieve precipitation strengthening [1-6]. In contrast, in some HSLA steels such as reactor pressure vessel steel, $\mathrm{Cu}$ often is considered as a solute impurity that induces destructive embrittlement when subjected to long-term neutron irradiation at $\sim 400{ }^{\circ} \mathrm{C}$ [7-13]. Therefore, it is important to tailor the precipitation morphology of $\mathrm{Cu}$-rich precipitates (CRPs) for attaining desired strength and toughness balance.

Actually, the characteristics of CRPs in aspect of size, number density, shape, etc., that determine final mechanical properties are largely dependent of the compositional and resultant structural evolution during heat treatment process, and the segregation of $\mathrm{Ni}$ and $\mathrm{Mn}$ at the precipitate/matrix interface significantly prohibits the growth of CRPs to large size [14-21]. In additional, the compositional evolution of CRPs provides important information for composition modification, processing optimization, and property improvement of $\mathrm{Cu}$-containing steels. However, 
the size-dependent compositional evolution of CRPs has not been thoroughly clarified. In this paper, the CRPs formed in an isothermally aged HSLA steel were studied by atom probe tomography (APT), especially focusing on the compositional and morphological evolution of CRPs at their different precipitation stages.

\section{Material and Experimental}

The steel used was prepared by vacuum induction melting and cast into an $80 \mathrm{~kg}$ ingot. After homogenization and forging, the ingot was hot-rolled into the plate with a thickness reduction from 140 to $32 \mathrm{~mm}$ followed by air cooling. The steel plate was fully austenitized and solutionized at $900{ }^{\circ} \mathrm{C}$ for $30 \mathrm{~min}$ followed by quenching in water and then isothermally aged at $500{ }^{\circ} \mathrm{C}$ for $1,4,16$, and $64 \mathrm{~h}$. The nominal chemical composition of the steel is $0.04 \mathrm{C}, 0.24 \mathrm{Si}, 0.84 \mathrm{Mn}, 1.15 \mathrm{Cu}, 1.94 \mathrm{Ni}, 0.51 \mathrm{Mo}, 0.50$ $\mathrm{Cr}, 0.043 \mathrm{Nb}, 0.009 \mathrm{Ti}, 0.03 \mathrm{Al}, 0.004 \mathrm{~N}, 0.007 \mathrm{P}$, and $0.004 \mathrm{~S}(\mathrm{wt} \%)$.

The APT experiment, using an advanced Imago (now Cameca Instruments) local electrode atom probe (LEAP, 3000 HR, CAMECA, Gennevilliers, France) using voltage pulsing mode, was performed at a residual pressure of $\sim 3 \times 10^{-9} \mathrm{~Pa}$ and the specimen temperature of $-223{ }^{\circ} \mathrm{C}$, and with a pulse repetition frequency of $200 \mathrm{kHz}$, the pulse-voltage to dc-voltage ratio of $15 \%$. The specimen for APT was prepared by using a standard twostage electropolishing method [22]. Data analysis was performed by using the Imago Visualization and Analysis Software (IVAS). The Cu-rich precipitates (CRPs) are identified by 10 at.\% $\mathrm{Cu}$ isoconcentration surfaces, and their sizes were represented by the diameter $(D)$ of equivalent spherical volume of the surface.

\section{Results and Discussion}

Figure 1 shows APT reconstructed 3D distribution maps of the $\mathrm{Cu}$-rich precipitates (CRPs) in the steel samples aged at $500{ }^{\circ} \mathrm{C}$ for different time. Generally, the CRPs increase in size and decrease in number density and evolve from initially spheroidal to more ellipsoidal or rodlike in morphology with prolonged aging time from 1 to $64 \mathrm{~h}$. The nanoscale CRPs or $\mathrm{Cu}$-rich clusters are almost uniformly distributed at their early nucleation stage, as shown in Fig. 1a. The formation of $\mathrm{Cu}$ nuclei can be promoted by Ni-rich clusters which are prevailingly formed during aging of $\mathrm{Cu}$ - and Ni-bearing steels [23]. The CRPs can directly nucleate in the $\mathrm{Cu}$ supersaturated ferritic matrix with the assisting of Ni-rich clusters and therefore exhibit a random distribution in the ferritic matrix. On the other hand, the nucleation and growth CRPs are more readily to correlate with the crystallographic defects such as dislocations and martensite lath boundaries LBs [24], which provide relative fast solute diffusion pathways of $\mathrm{Cu}$ atoms. The arrangements of CRPs in Fig. 1b probably outline these linear defects. Taking the scale of reconstructed maps into consideration, the CRPs in Fig. 1c are comparable in size to those in Fig. 1b. The CRPs undergo limited growth when the holding time prolonged form 4 to $16 \mathrm{~h}$. One promising explanation is that $\mathrm{Ni}$ and $\mathrm{Mn}$ tend to segregate at the precipitate/matrix heterophase interfaces and therefore impede rapid growth of the CRPs [25-27]. Notably, some CRPs locate out of the atom map in Fig. 1c, because the reconstructed volume is relatively small. The presence of rodlike CRPs in Fig. 1d indicates the late growth stage of CRPs at aging for $64 \mathrm{~h}$. However, not all CRPs are rodlike but most of them are larger in size than those formed for shorter aging time (Fig. 1a-c). This is probably attributed to the fact that the larger precipitates grow at expend of the smaller ones during the ripening process.

The size distribution of CRPs in the steel samples aged at $500{ }^{\circ} \mathrm{C}$ for different time is shown in Fig. 2, where the average size (precipitate diameter, $D_{\mathrm{p}}$ ) and number densities $(N v)$ are also indicated. The size region of the CRPs with the highest frequency that represents the most prevailing CRPs gradually shifts from $2-3$ to $4-5 \mathrm{~nm}$ with prolonged aging time from 1 to $64 \mathrm{~h}$. Note, the CRPs will be underestimated in average size when some of the precipitates are partly located out of the APT reconstructed volume (see Fig. 1c). As a result, the frequency of smaller CRPs between 2 and $3 \mathrm{~nm}$ is exceptionally enhanced in Fig. 2c. The average size of CRPs increases from $(2.37 \pm 0.48)$ to $(4.81 \pm 1.46) \mathrm{nm}$ with prolonged aging time. In addition, the standard deviation of the average size also gradually increases. It is possibly attributed to the presence of small CRPs that are either resulted from the coarsening of the precipitates or related to the limited APT reconstructed volume. The number density of the CRPs generally decreases from $(1.19 \pm 0.29) \times 10^{23}$ to $(1.95 \pm 0.35) \times 10^{22} \mathrm{~m}^{-3}$ with prolonged aging time. However, the precipitate density at $4 \mathrm{~h}$ aging $\left[(4.64 \pm 0.47) \times 10^{22} \mathrm{~m}^{-3}\right]$ is relatively smaller than that at $16 \mathrm{~h}$ aging $\left[(5.32 \pm 0.76) \times 10^{22} \mathrm{~m}^{-3}\right]$. The unordinary phenomena are possibly ascribed to the smaller APT data set in Fig. 1c. In addition, the preferential formation of CRPs at crystallographic defects often creates precipitatefree zones (PRZs) in the ferritic matrix [24]. When the PFZs are incorporated in the APT reconstructed volume, the number density of CRPs will be accordingly underestimated (Fig. 2b), and vice versa.

Figure 3 gives the proxigram concentration profiles of the selected CRPs marked by arrows in Fig. 1, where the morphology (shown by APT reconstructed map), size 


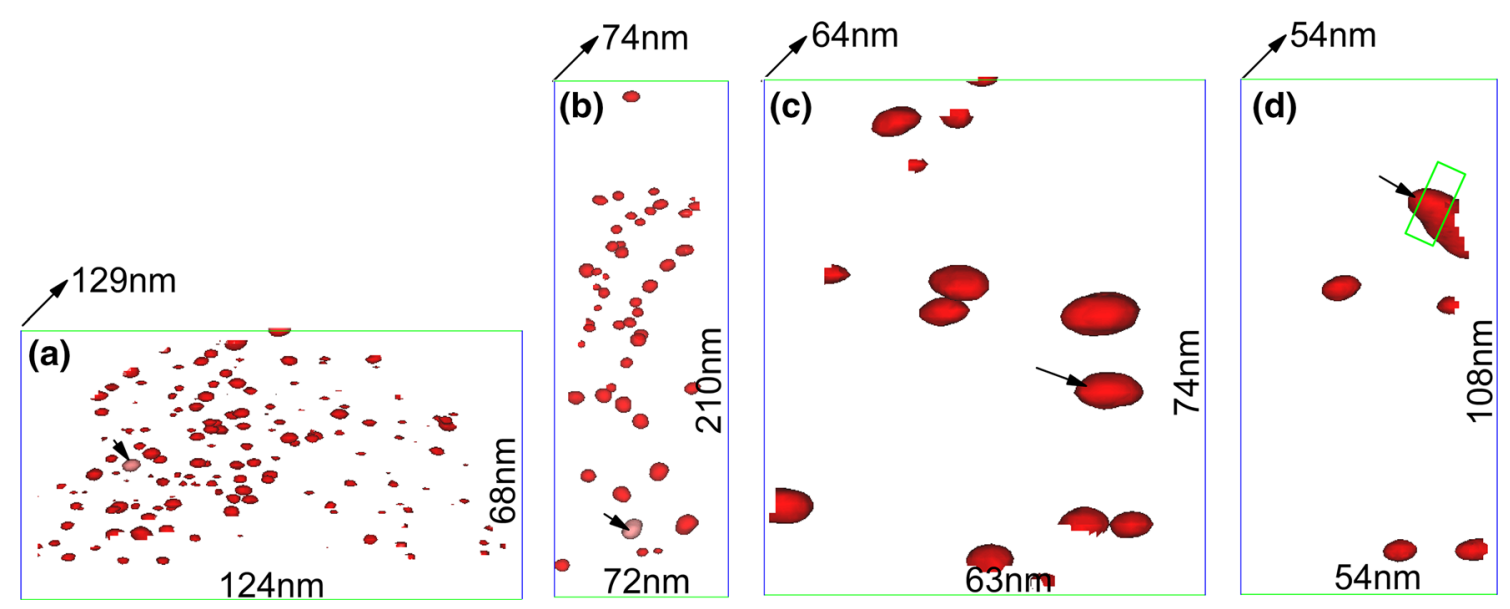

Fig. 1 APT reconstructed 3D distribution map of CRPs delineated by 10 at.\% $\mathrm{Cu}$ isoconcentration surfaces in the steel samples isothermally aged at $500{ }^{\circ} \mathrm{C}$ for $\mathbf{a} 1 \mathrm{~h}, \mathbf{b} 4 \mathrm{~h}, \mathbf{c} 16 \mathrm{~h}, \mathbf{d} 64 \mathrm{~h}$. The CRPs marked by arrow are selected for further composition analysis

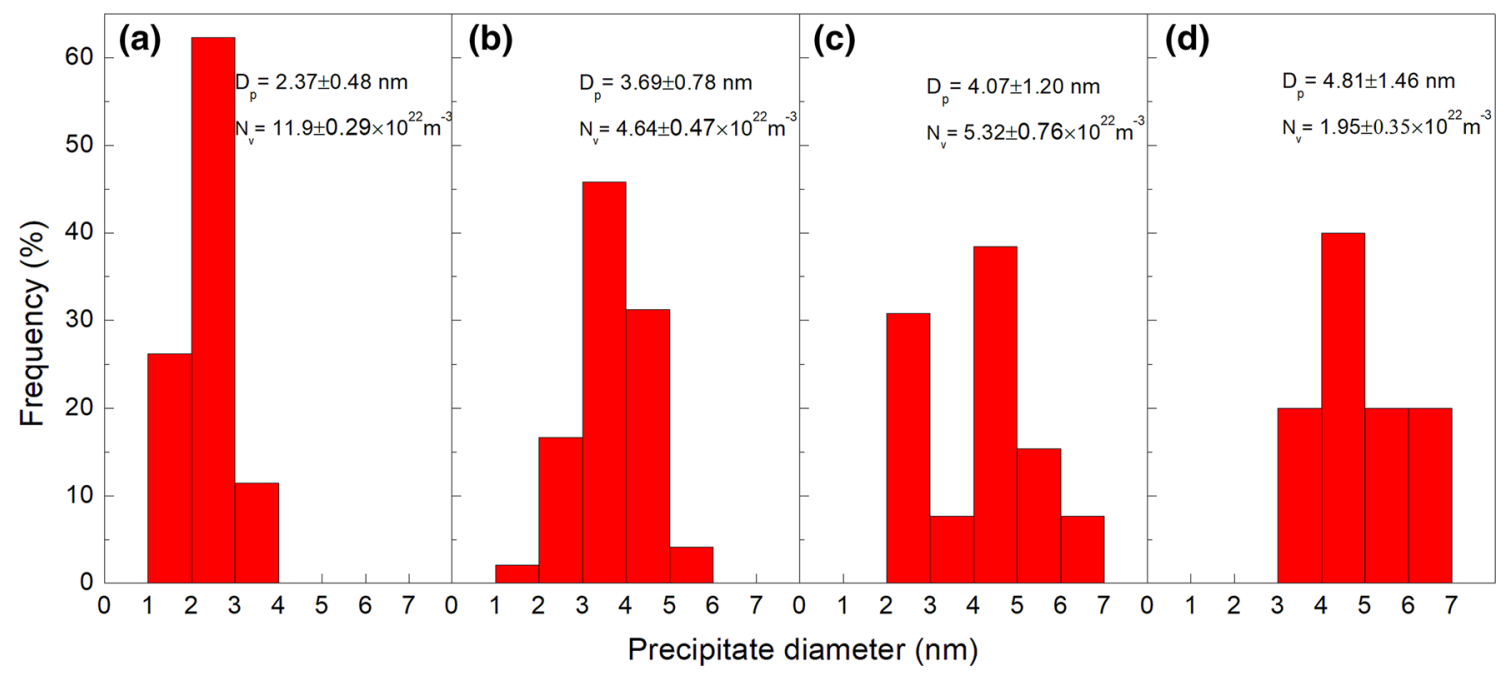

Fig. 2 Size distribution integrated with the average diameter $\left(D_{\mathrm{p}}\right)$, number density $\left(N_{\mathrm{v}}\right)$ of the CRPs in the steel samples quenched and aged at $500{ }^{\circ} \mathrm{C}$ for a $1 \mathrm{~h}, \mathbf{b} 4 \mathrm{~h}, \mathbf{c} 16 \mathrm{~h}, \mathbf{d} 64 \mathrm{~h}$

(represented by equivalent diameter, D), and compositions (within 10 at.\% $\mathrm{Cu}$ isoconcentration surfaces) of the precipitates are also indicated. With prolonged aging time, the selected individual CRPs gradually increase from 6.6 to $13.2 \mathrm{~nm}$ in size and accordingly evolve from spheroidal to more ellipsoidal or rodlike in morphology. Meanwhile, the CRPs are rich in different amount of $\mathrm{Fe}, \mathrm{Ni}$ and $\mathrm{Mn}$. It seems that the CRP at aging for $1 \mathrm{~h}$ contains less $\mathrm{Cu}$ than that in the other aging conditions and thus is likely rich in more $\mathrm{Fe}$, Ni and $\mathrm{Mn}$. In light of the quantitative compositions, the CRPs contain less $\mathrm{Fe}$ and more $\mathrm{Cu}$ as well as slightly decreased $\mathrm{Ni}$ and gradually increased $\mathrm{Mn}$ in content. However, these solute atoms, especially $\mathrm{Ni}$ and $\mathrm{Mn}$, are heterogeneously distributed from the matrix to the precipitate interiors, as indicated by the proxigram concentration profiles. When the CRP is relatively small (Fig. 3a), the precipitate interior contains $\sim 75$ at.\% $\mathrm{Cu}$ and more than 20 at.\% Fe as well as a comparatively high amount of $\mathrm{Ni}$ and $\mathrm{Mn}$. Moreover, the deviations of the concentrations of individual solute atoms are relatively high due to the low total amount of atoms analyzed in every bin volume. When the CRPs increase in size with prolonged aging time (Figs. 3b-d), the precipitates contain as high as $\sim 90$ at. $\% \mathrm{Cu}$ and nearly $\sim 0$ at. $\% \mathrm{Fe}$ as well as decreased $\mathrm{Ni}$ and $\mathrm{Mn}$, which are the compositions of typical CRPs in equilibrium state. $\mathrm{Ni}$ and $\mathrm{Mn}$ are likely prone to segregate at the precipitate/matrix heterophase interfaces. However, the intensity of segregation is different for the CRPs with different sizes. With increased size of the selected CRPs in an order of $7.6 \rightarrow 9.2 \rightarrow 13.2 \mathrm{~nm}$, the peak concentrations of $\mathrm{Ni}$ and $\mathrm{Mn}$ at the precipitate/matrix interfaces increase roughly in the order of $5 \rightarrow 6 \rightarrow 8$ at.\% and $4 \rightarrow 5 \rightarrow 6$ at.\%, respectively. In addition, considering the initial nominal composition of the steel, Mn generally 

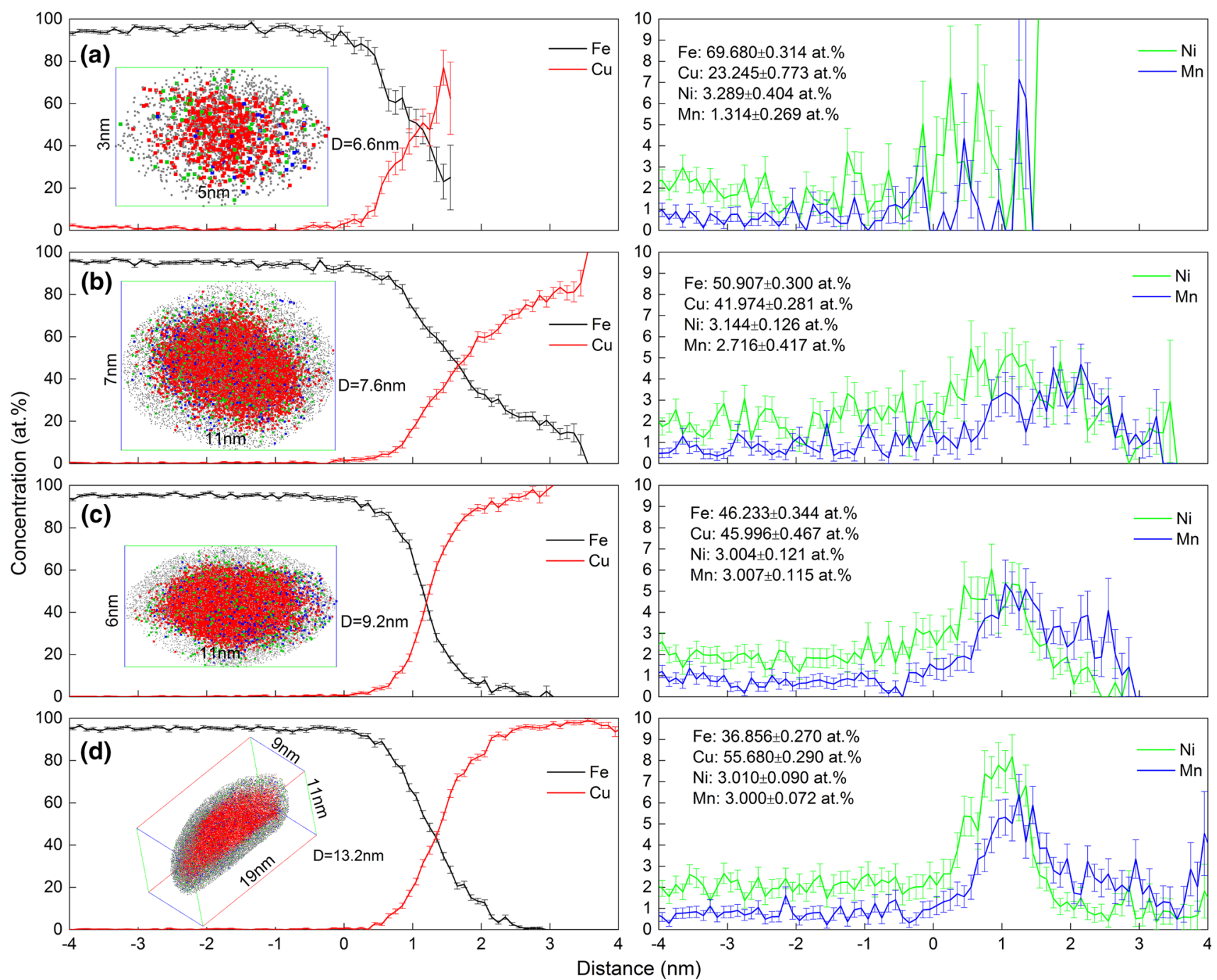

Fig. 3 Proxigram concentration profiles for $\mathrm{Fe}, \mathrm{Cu}, \mathrm{Ni}$, and $\mathrm{Mn}$ with respect to 10 at.\% $\mathrm{Cu}$ isoconcentration surfaces of the selected $\mathrm{CRPs}$ marked by arrow in Fig. 1, integrated with the APT reconstructed 3D atom maps, equivalent diameters, $\mathrm{D}_{\mathrm{p}}$, and composition of the separate CRPs. Steel samples aged at $500{ }^{\circ} \mathrm{C}$ for a $1 \mathrm{~h}, \mathbf{b} 4 \mathrm{~h}, \mathbf{c} 16 \mathrm{~h}, \mathbf{d} 64 \mathrm{~h}$

exhibits stronger tendency of enrichment than $\mathrm{Ni}$ in the precipitate interior, which suggests $\mathrm{Mn}$ is more readily to stay in the precipitate interior especially for the CRPs with more equilibrium compositions and hence larger size.

Figure 4 gives detail APT analysis of a representative coarsen CRP in the steel sample aged at $500{ }^{\circ} \mathrm{C}$ for $64 \mathrm{~h}$, marked by green rectangle in Fig. 1d, showing (a) the 3D distribution of $\mathrm{Cu}, \mathrm{Ni}, \mathrm{Mn}, \mathrm{C}, \mathrm{Mo}, \mathrm{Cr}, \mathrm{Fe}$, and $\mathrm{Si}$ and (b) the corresponding 1D composition profile along $\mathrm{Z}$ direction (blue line) in (a). Most of $\mathrm{Cu}$ precipitates out to contribute the formation of coarsened CRP, thereby leading to $\mathrm{Cu}$ depletion in the surround ferritic matrix. Only a limited few $\mathrm{Fe}$ and $\mathrm{Ni}$ are found in the CRP's interior, whereas Mn seemingly tends to retain within, as shown in Fig. 4b. Although both $\mathrm{Ni}$ and $\mathrm{Mn}$ are readily segregate at the precipitate/matrix boundary, $\mathrm{Mn}$ is prone to "stay" in the CRP's interior. Taking the nominal composition into account, it seems that the CRP contains comparable amount of Ni and higher amount of Mn compared with the initial content in solution. This means that $\mathrm{Mn}$ is more readily to enrich in the CRP's interior other than segregate at the precipitate/matrix interface. In addition, the fact the CRP depletes with the carbide-forming elements $\mathrm{Mo}, \mathrm{Cr}$, and $\mathrm{C}$, as shown by atom distribution maps and composition profile, and makes the co-precipitation of CRPs with alloyed carbide thermodynamically possible. Moreover, the CRP is free of Si that tends to diffuse toward the ferritic matrix during CRPs' growth [17].

Figure 5 displays schematic illustration of compositional evolution of the CRPs. At the early nucleation stage, $\mathrm{Cu}$ atoms diffuse to replace $\mathrm{Fe}$ atoms in the crystal lattice of ferritic matrix and further to form the nanoscale $\mathrm{Cu}$-rich clusters. At the initial nucleation stage, $\mathrm{Fe}, \mathrm{Cu}, \mathrm{Ni}$, and $\mathrm{Mn}$ are generally randomly distributed, as shown in Fig. 4a. 

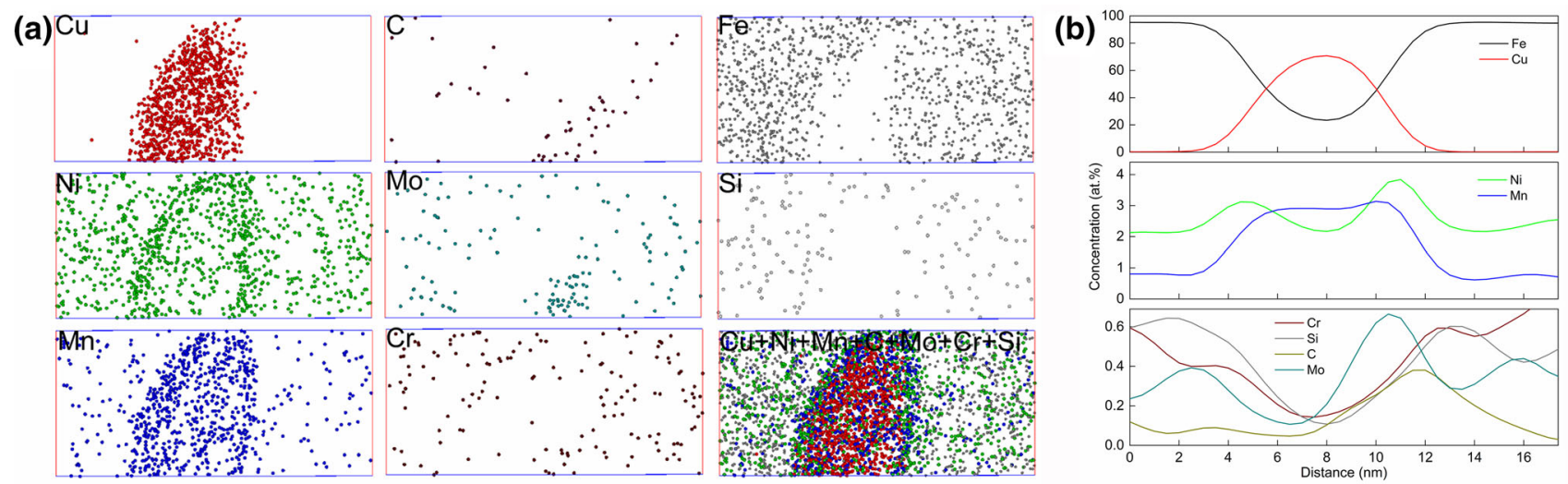

Fig. 4 a APT reconstructed 3D atom distribution map of $\mathrm{Cu}, \mathrm{Ni}, \mathrm{Mn}, \mathrm{C}, \mathrm{Cr}, \mathrm{Mo}, \mathrm{Si}$, and $\mathrm{Fe}$ atoms in and around a selected CRP with elongated rod-shaped marked green rectangle in Fig. 1d. b Composition profile of the CRP along Z direction (blue line) in a, showing the redistribution behavior of the solute atoms across the precipitate. Sample tempered at $500{ }^{\circ} \mathrm{C}$ for $64 \mathrm{~h}$
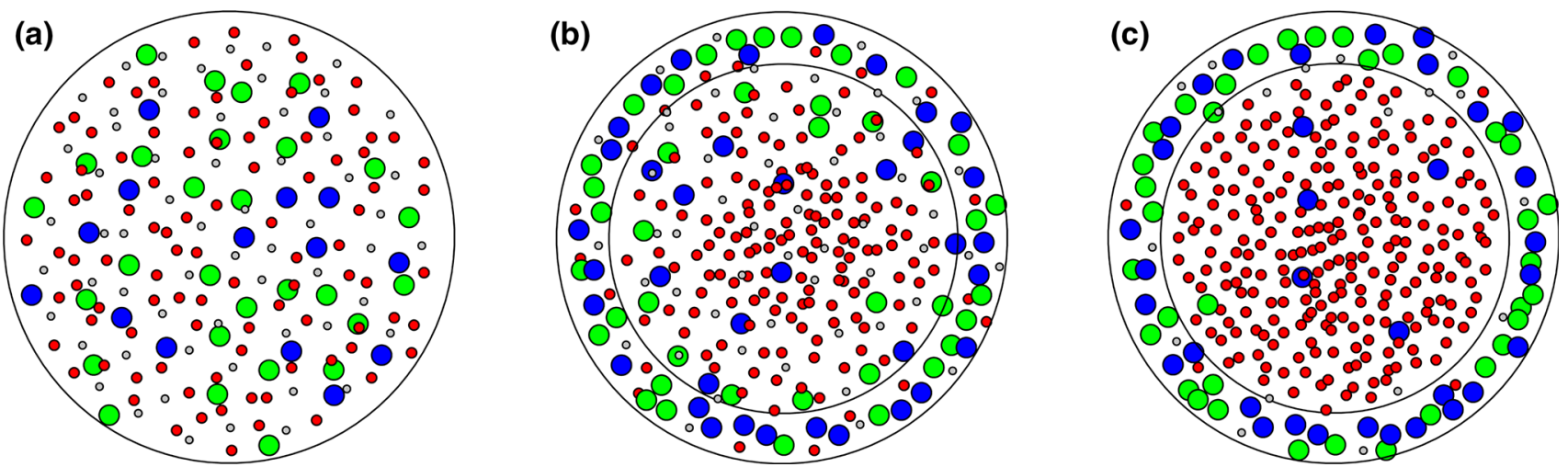

Fig. 5 Schematic illustration of compositional evolution of CRPs showing the distribution of $\mathrm{Cu}$ (red), $\mathrm{Fe}$ (gray), $\mathrm{Ni}$ (green), and Mn (blue) in the CRPs approaching their equilibrium composition

The crystallographic defects and the preexisting Ni-rich cluster would promote the $\mathrm{Cu}$ clustering. The $\mathrm{Cu}$-rich clusters are considered to be BCC-structured and coherent with the surrounding ferritic matrix [28-30]. During the growth of the $\mathrm{Cu}$-rich clusters, $\mathrm{Fe}$ is continuously depleted into ferritic matrix and, $\mathrm{Ni}$ and $\mathrm{Mn}$ gradually diffuse to the precipitate/matrix heterophase interface, contributing to the development of a composition induced core-shell structure. At the same time, the structure of the CRPs evolves from BCC to transitional structures of $9 R$ and $3 R$. The compositional and structural evolution is thought to largely reduce the strain energy and interfacial energy [31, 32]. With the growth process proceeding, the CRPs eventually reach their equilibrium composition with only a little $\mathrm{Fe}$ and $\mathrm{Ni}$ but some $\mathrm{Mn}$ in the precipitate interior. $\mathrm{Ni}$ and most of $\mathrm{Mn}$ segregate at the precipitate/matrix interface to inhibit fast coarsening of the CRPs, and $\mathrm{Fe}$ is almost expelled into the matrix. Meanwhile, a FCC structure is formed along with the development of an ellipsoidal or rodlike morphology [17].

\section{Conclusion}

The $\mathrm{Cu}$ precipitation in a high-strength low-alloy steel isothermally aged at $500{ }^{\circ} \mathrm{C}$ for different time is characterized by using atom probe tomography. With prolonged aging time at $500^{\circ} \mathrm{C}$, the CRPs generally increase in size and decrease in number density, and gradually evolve from spherical to more ellipsoidal in morphology. The small CRPs are rich in a relatively high amount of $\mathrm{Fe}$ and a certain amount of $\mathrm{Ni}$ and $\mathrm{Mn}$, and these atoms exhibit relatively high composition deviation. The large CRPs contain more $\mathrm{Cu}$ and less $\mathrm{Fe}$. $\mathrm{Ni}$ and $\mathrm{Mn}$ are readily to segregate at the $\mathrm{Cu}$-rich precipitate/matrix interface. The concentration of $\mathrm{Mn}$ is higher than that of $\mathrm{Ni}$ in the precipitate interior especially when the precipitate is large in size. Compared to $\mathrm{Ni}, \mathrm{Mn}$ is more readily to enrich in the CRP's interior other than segregate at the precipitate/matrix interface. In addition, the formation of CRPs is in association with alloyed carbide. 
Acknowledgements One of the authors, Qingdong Liu, thanks to Mrs Qifeng Zeng at Shanghai Nuclear Engineering and Research \& Design Institute, China, for her great support to this research.

\section{References}

[1] E.J. Czyryca, R.E. Link, R.J. Wong, D.A. Aylor, T.W. Montemarano, J.P. Gudas, Nav. Eng. J. 102, 63 (1990)

[2] S. Thompson, G. Krauss, Metall. Mater. Trans. A 27, 1573 (1996)

[3] S. Vaynman, D. Isheim, R.P. Kolli, S.P. Bhat, D.N. Seidman, M.E. Fine, Metall. Mater. Trans. A 39, 363 (2008)

[4] R.D.K. Misra, Z. Jia, R. O'Malley, S.J. Jansto. Mater. Sci. Eng. A 528, 8772 (2011)

[5] Z. Zhang, C. Liu, Y. Wen, A. Hirata, S. Guo, G. Chen, M. Chen, B. Chin, Metall. Mater. Trans. A 43, 351 (2012)

[6] R.P. Kolli, D.N. Seidman, in Heat Treatment of Copper Precipitation-Strengthened Steels, ASM Handbook, Volume 4D, Heat Treating of Irons and Steels, ed by J. Dossett, G.E. Totten (ASM International, Materials Park 2014), pp. 188

[7] G.E. Lucas, J. Nucl. Mater. 407, 59 (2010)

[8] Reports: Integrity of Reactor Pressure Vessels in Nuclear Power Plants: Assessment of Irradiation Embrittlement Effects in Reactor Pressure Vessel Steels, IAEA Nuclear Energy Series. No. NP-T-3.11. International Atomic Agency, Vienna, 2009

[9] G.R. Odette, B.D. Wirth, D.J. Bacon, N.M. Ghoniem, MRS Bull. 26, 176 (2001)

[10] T. Takeuchi, A. Kuramoto, J. Kameda, T. Toyama, Y. Nagai, M. Hasegawa, T. Ohkubo, T. Yoshiie, Y. Nishiyama, K. Onizawa, J. Nucl. Mater. 402, 93 (2010)

[11] M.K. Miller, K.F. Russell, J. Nucl. Mater. 372, 145 (2007)

[12] G. Xu, L.L. Cai, L. Feng, B.X. Zhou, J.A. Wang, H.S. Zhang, Acta Metall. Sin. 48, 753 (2012). (in Chinese)
[13] Z. Lu, Acta Metall. Sin. 47, 777 (2011). (in Chinese)

[14] D. Isheim, R.P. Kolli, M.E. Fine, D.N. Seidman, Scr. Mater. 55, 35 (2006)

[15] R.P. Kolli, D.N. Seidman, Microsc. Microanal. 13, 272 (2007)

[16] R.P. Kolli, Z. Mao, D.T. Keane, D.N. Seidman, Appl. Phys. Lett. 91, 241903 (2007)

[17] R.P. Kolli, D.N. Seidman, Acta Mater. 56, 2073 (2008)

[18] M.D. Mulholland, D.N. Seidman, Scr. Mater. 60, 992 (2009)

[19] M.D. Mulholland, D.N. Seidman, Acta Mater. 59, 1881 (2011)

[20] Z.W. Zhang, C.T. Liu, M.K. Miller, X. Wang, Y.R. Wen, T. Fujita, A. Hirata, M.W. Chen, G. Chen, B.A. Chin, Sci. Rep. 3, 1327 (2013)

[21] R.P. Kolli, D.N. Seidman, Microsc. Microanal. 20, 1727 (2014)

[22] M.K. Miller, Atom Probe Tomography: Analysis at the Atomic Level (Kluwer Academic/Plenum Publishers, New York, 2000), p. 26

[23] Q.D. Liu, J.F. Gu, W.Q. Liu. Metall. Mater. Trans. A 44, 4434 (2013)

[24] Q.D. Liu, S.J. Zhao, MRS Commun. 4, 127 (2012)

[25] B.L. Tiemens, A.K. Sachdev, R.K. Mishra, G.B. Olson, Metall. Mater. Trans. A 43, 3626 (2012)

[26] Q.D. Liu, W.Q. Liu, X.Y. Xiong, J. Mater. Res. 27, 1060 (2012)

[27] Q.D. Liu, S.J. Zhao, Metall. Mater. Trans. A 44, 163 (2013)

[28] R. Monzen, M. Iguchi, M.L. Jenkins, Philos. Mag. Lett. 80, 137 (2000)

[29] P.J. Othen, M.L. Jenkins, G.D.W. Smith, Philos. Mag. A 70, 1 (1994)

[30] R. Monzen, M.L. Jenkins, A.P. Sutton, Philos. Mag. 80, 711 (2000)

[31] G. Xu, D.F. Chu, L.L. Cai, B.X. Zhou, W. Wang, J.C. Peng, Acta Metall. Sin. 47, 905 (2011). (in Chinese)

[32] R. Monzen, K. Takada, C. Watanabe, ISIJ Int. 44, 442 (2004) 